\title{
Measuring Average Rate of Return of Pensions: A Discrete, Stochastic and Continuous Price Index Approaches
}

\author{
Jacek Białek $^{1}$ \\ ${ }^{1}$ Department of Statistical Methods, Institute of Statistics and Demography, University of Łódź, Łódź, Poland \\ Correspondence: Jacek Białek, Department of Statistical Methods, Institute of Statistics and Demography, Univer- \\ sity of Łódź, 3/5 Polskiej Organizacji Wojskowej St., Łódź 90-255, Poland. E-mail: jbialek@uni.lodz.pl
}

Received: July 28, 2013 Accepted: September 15, 2013 Online Published: October 11, 2013

doi:10.5539/ijsp.v2n4p56

URL: http://dx.doi.org/10.5539/ijsp.v2n4p56

\begin{abstract}
In this paper the problem of the proper construction of the average rate of return (ARR) of pension (or investment) funds is considered, using a chain price index approach. Some known formulas of the ARR can be expressed by chain indices. The paper proposes and discusses a continuous-time formula. The prices and the number of the participating units are assumed to be continuous-time stochastic processes. Using the Ito theorem (Ito, 1951) it is proved that the relative change in net assets of funds equals a product of relative changes in unit prices and number of fund clients. Simulation study compares the discrete time formulas and the continuous formula in some illustrative case.
\end{abstract}

Keywords: investment funds, pension funds, average rate of return of funds, price index theory, continuous time stochastic model, Wiener process, chain indices, minimal rate of return

\section{Introduction}

Efficiency of pension or investment funds is measured in many different ways (Białek, 2008, 2009). These measures should be properly defined. Efficiency in this context is meant to indicate changes of fund assets connected with any investment. The information about the average return of a group of funds is very important both for fund clients and fund managers. Firstly, it allows to compare the financial outcome of the given fund to the rest of funds. It helps customers in making a decision about money allocation. Secondly, the average return of investment funds from different sectors (manufacturing, agricultural, service etc.) provides important information about the financial situation within these sectors. And thirdly, for pension funds, we can find legal regulations defining the minimal rate of return of funds based on the average rate of return. For example, in the Polish legal regulations (Polish Pension Reform Package, 1997) the minimal rate of return is defined as a half of the average return of a group of funds or the average return minus four percentage points (depending on which of these values is higher). In case of deficit the corresponding fund has to cover it. It is always a very dangerous situation for the fund (Note 1). Under the Polish law the average rate of return (ARR) of a group of pension funds is defined as follows:

$$
\bar{r}_{0}\left(T_{1}, T_{2}\right)=\sum_{i=1}^{n} \frac{1}{2} r_{i}\left(T_{1}, T_{2}\right) \cdot\left(\frac{A_{i}\left(T_{1}\right)}{\sum_{i=1}^{n} A_{i}\left(T_{1}\right)}+\frac{A_{i}\left(T_{2}\right)}{\sum_{i=1}^{n} A_{i}\left(T_{2}\right)}\right)
$$

where $r_{i}\left(T_{1}, T_{2}\right)$ denotes the rate of return of the $i^{\text {th }}$ fund during a given time period $\left[T_{1}, T_{2}\right]$ and $A_{i}(t)$ denotes the value of $i^{\text {th }}$ fund assets at time $t$. Since 2004 the results of funds for the last 36 months are verified twice a year. There are may arguments for searching new definitions of the ARR of a group of funds (Gajek \& Kałuszka, 2000), our propositions for a discrete time can be found in (Białek, 2009). The paper is organized as follows: Section 2 gives the economic postulates for the ARR and presents some discrete formulas. It is shown that the discrete measures can be expressed by chain indices. Section 3 presents and discusses an analogical formula for the continuous time, where the prices and the number of the participating units are assumed to be continuous-time stochastic processes. Simulation study results are given in Section 4 , where it is shown that presented discrete formulas and the continuous formula approximate each other.

\section{Economic Postulates and Discrete Formulas of the ARR}

At first sight the problem of constructing the ARR of funds seems to be straightforward. But if we look at postulates 
of Gajek and Kałuszka propose seven economic postulates (Białek, 2005) and they prove that the Polish measure violates four of these postulates. Moreover, Gajek and Kałuszka (2001) propose their own definition of the average rate of return of funds:

$$
\bar{r}_{G K}\left(T_{1}, T_{2}\right)=\prod_{t=T_{1}}^{T_{2}-1}\left(1+\sum_{i=1}^{n} A_{i}^{*}(t) r_{i}(t, t+1)\right)-1,
$$

where

$$
A_{i}^{*}(t)=\frac{A_{i}(t)}{\sum_{i=1}^{n} A_{i}(t)}=\frac{p_{i}(t) q_{i}(t)}{\sum_{i=1}^{n} p_{i}(t) q_{i}(t)}
$$

and $p_{i}(t)$ denotes the value of the participation unit of the $i^{t h}$ fund at time $t$ and $q_{i}(t)$ denotes the number of units of the $i^{\text {th }}$ fund at time $t$. In this Section, a group of funds is considered as an aggregate containing $n$ commodities (funds) with prices $p_{i}(t)$ and quantities $q_{i}(t)$, where $t \in\left[T_{1}, T_{2}\right]$. Let us denote by $P^{L}(t, t+1)$ the Laspeyres price index, where

$$
P^{L}(t, t+1)=\frac{\sum_{i=1}^{n} q_{i}(t) p_{i}(t+1)}{\sum_{i=1}^{n} q_{i}(t) p_{i}(t)}
$$

and the logarithmic Laspeyres price index as follows (Lippe, 2007):

$$
P^{L L}(t, t+1)=\prod_{i=1}^{n}\left(\frac{p_{i}(t+1)}{p_{i}(t)}\right)^{A_{i}^{*}(t)}
$$

Equation (2) could be incorporated with Equation (5), using the Laspeyres chain index (Białek, 2012) as follows:

$$
\prod_{t=T_{1}}^{T_{2}-1} P^{L}(t, t+1)-1=\prod_{t=T_{1}}^{T_{2}-1}\left(1+\sum_{i=1}^{n} \frac{q_{i}(t) p_{i}(t)}{\sum_{i=1}^{n} q_{i}(t) p_{i}(t)} \cdot \frac{p_{i}(t+1)-p_{i}(t)}{p_{i}(t)}\right)-1=\bar{r}_{G K}\left(T_{1}, T_{2}\right) .
$$

Białek proposes another definition of the ARR, where $\bar{r}_{B}$ can be written using Equation (5) as follows (Białek, 2012):

$$
\bar{r}_{B}\left(T_{1}, T_{2}\right)=\prod_{t=T_{1}}^{T_{2}-1} P^{L L}(t, t+1)-1=\prod_{t=T_{1}}^{T_{2}-1} \prod_{i=1}^{n}\left(\frac{p_{i}(t+1)}{p_{i}(t)}\right)^{A_{i}^{*}(t)}-1=\prod_{t=T_{1}}^{T_{2}-1} \exp \left(\sum_{i=1}^{n} A_{i}^{*}(t) \ln \frac{p_{i}(t+1)}{p_{i}(t)}\right)-1 .
$$

The two measures $\bar{r}_{G K}$ and $\bar{r}_{B}$ satisfy all the postulates from Gajek and Kałuszka, 2000). It can be shown that $\bar{r}_{B}\left(T_{1}, T_{2}\right) \leq \bar{r}_{G K}\left(T_{1}, T_{2}\right)$. Moreover, if $p_{i}(t+1) \approx p_{i}(t)$ for each iand $t \in\left[T_{1}, T_{2}\right]$, then $\bar{r}_{B}\left(T_{1}, T_{2}\right) \approx \bar{r}_{G K}\left(T_{1}, T_{2}\right)$. Gajek and Kałuszka claim that the Polish measure defined in (1) overestimates the real value of the average rate of return of funds. Gajek and Kałuszka consider not only the discrete stochastic model but they also propose continuous (deterministic and stochastic) measures (Gajek \& Kałuszka, 2002). In the next Section, an original, stochastic and continuous measure of the average return is presented. It seems to be a natural next step in using the chain index theory for constructing the average rate of return of funds.

\section{Continuous Time Stochastic Model}

Let $\left\{p_{i}(t): t \geq 0\right\}$ denote the stochastic process of the price of unit of $i^{t h}$ fund $(i=1,2, \ldots, n)$ defined on a probability space $(\Omega, \mathfrak{J}, P)$ and let $\left\{q_{i}(t): t \geq 0\right\}$ denote the stochastic process of the number of units of $i^{t h}$ fund defined on the same probability space. Let $F=\left\{\mathfrak{J}_{t}: t=0,1,2, \ldots\right\}$ be a filtration, i.e. each $\mathfrak{J}_{t}$ is an algebra of $\Omega$ with $\mathfrak{J}_{0} \subseteq \mathfrak{J}_{s} \subseteq \mathfrak{J}_{t} \subseteq \mathfrak{J}$ for any $s<t$. Without loss of generality, $\mathfrak{J}_{0}=\{\varnothing, \Omega\}$ is assumed. The filtration $F$ describes how the information about the market is revealed to the observer. Processes $p_{i}(t)$ and $q_{i}(t)$ are assumed to be progressively measurable with respect to the family $\left\{\mathfrak{I}_{t}: t \geq 0\right\}$. In practice, the price and quantity processes have positive values. Thus in finance, the processes of share prices are often described by the geometric Brownian (Wiener) motion (Note 2) (also known as exponential Brownian motion) as follows (Koo, 1998):

$$
d p_{i}(t)=\alpha_{i} p_{i}(t) d t+\beta_{i} p_{i}(t) d W_{i}(t), i \in\{1,2, \ldots, n\}
$$

where the percentage drift $\alpha_{i}$ and the percentage volatility $\beta_{i}$ are constants, $W_{i}(t)$ denotes the standard Wiener process. For an arbitrary initial real value $p_{i}(0)$ the stochastic differential Equation (8) has the analytic solution (under Ito's interpretation: (Ito, 1951)),

$$
p_{i}(t)=p_{i}(0) \exp \left(\left(\alpha_{i}-\frac{\beta_{i}^{2}}{2}\right) t+\beta_{i} W_{i}(t)\right), i \in\{1,2, \ldots, n\} .
$$


Thus the price processes described in (9) have always positive values and additionally $p_{i}(t)$ is log-normally distributed (Oksendal, 2002).

Let us assume that not only prices of units are described by the geometric Wiener process but also processes of number of units of funds are described as follows:

$$
d q_{i}(t)=\gamma_{i} q_{i}(t) d t+\theta_{i} q_{i}(t) d W_{i}(t), i \in\{1,2, \ldots, n\},
$$

where the percentage drift $\gamma_{i}$ and the percentage volatility $\theta_{i}$ are constants. Hence,

$$
q_{i}(t)=q_{i}(0) \exp \left(\left(\gamma_{i}-\frac{\theta_{i}^{2}}{2}\right) t+\theta_{i} W_{i}(t)\right), i \in\{1,2, \ldots, n\} .
$$

Under above assumptions the following definition of the ARR of a group of funds on a time interval $\left[T_{1}, T_{2}\right]$ is proposed:

$$
\begin{aligned}
R_{P}\left(T_{1}, T_{2}\right)= & \exp \left[\int _ { T _ { 1 } } ^ { T _ { 2 } } \left(\sum_{i=1}^{n} A_{i}^{*}(t) \alpha_{i}+\frac{1}{2} \sum_{i=1}^{n} A_{i}^{*}(t) \beta_{i} \theta_{i}-\frac{1}{2} \sum_{i=1}^{n}\left(A_{i}^{*}(t)\right)^{2} \beta_{i}^{2}-\right.\right. \\
& \left.\left.-\frac{1}{2} \sum_{i=1}^{n}\left(A_{i}^{*}(t)\right)^{2} \beta_{i} \theta_{i}\right) d t+\sum_{i=1}^{n} \int_{T_{1}}^{T_{2}} A_{i}^{*}(t) \beta_{i} d W_{i}(t)\right]-1,
\end{aligned}
$$

where, $A_{i}^{*}(t), \alpha_{i}, \beta_{i}, \theta_{i}, W_{i}(t)$ as defined above, and the integral on the right side of formula (12) is the Ito integral (Karatzas \& Shreve, 1991). In Equation (12), reducing the random factor connected with the Wiener process to equal zero, i.e., $\beta_{i}(t)=0$ and assuming $\alpha_{i}=d p_{i}(t) / d t$, we obtain,

$$
R_{P}\left(T_{1}, T_{2}\right)=\exp \left(\int_{T_{1}}^{T_{2}} \sum_{i=1}^{n} A_{i}^{*}(t) \alpha_{i} d t\right)-1=\exp \left(\int_{T_{1}}^{T_{2}} \sum_{i=1}^{n} A_{i}^{*}(t) d p_{i}(t)\right)-1=P^{D i v}\left(T_{1}, T_{2}\right)-1,
$$

where $P^{D i v}$ denotes the continuous Divisia price index (Banerjee, 1979; Hulten, 1973).

When $\beta_{i}(t)=0$ Equation (9) becomes:

$$
\frac{p_{i}\left(T_{2}\right)}{p_{i}\left(T_{1}\right)}=\exp \left[\alpha_{i}\left(T_{2}-T_{1}\right)\right]
$$

Using Equation (14), Equation (13) is reduced to:

$$
R_{p}\left(T_{1}, T_{2}\right)=\prod_{i=1}^{n}\left(\frac{p_{i}\left(T_{2}\right)}{p_{i}\left(T_{1}\right)}\right)^{w_{i}}-1=P^{C D}-1,
$$

where,

$$
w_{i}=\frac{\int_{T_{1}}^{T_{2}} A_{i}^{*}(t) d t}{T_{2}-T_{1}}
$$

and

$$
\sum_{i=1}^{n} w_{i}=\frac{1}{T_{2}-T_{1}} \sum_{i=1}^{n} \int_{T_{1}}^{T_{2}} A_{i}^{*}(t) d t=\frac{1}{T_{2}-T_{1}} \int_{T_{1}}^{T_{2}} \sum_{i=1}^{n} A_{i}^{*}(t) d t=\frac{1}{T_{2}-T_{1}} \int_{T_{1}}^{T_{2}} d t=1 .
$$

and $P^{C D}$ is the well known Cobb-Douglas price index (Lippe, 2007). From (6), (7), (13) and (15) we conclude that the stochastic proposition of the ARR is well-constructed. It has been proved (see Appendix) that in the stochastic case one of the most important postulates of Gajek and Kałuszka holds, namely:

$$
R_{A}\left(T_{1}, T_{2}\right)+1=\left(R_{P}\left(T_{1}, T_{2}\right)+1\right)\left(R_{Q}\left(T_{1}, T_{2}\right)+1\right),
$$

where $R_{A}\left(T_{1}, T_{2}\right)$ and $R_{Q}\left(T_{1}, T_{2}\right)$ denote respectively the relative change in net assets and the number of clients of funds.

\section{Simulation Study}

A group of $n=4$ funds were considered, the time horizon of observations $T=1$ and the following parameters of prices of units and numbers of units processes were assumed (Note 3):

(a) Prices of units:

$$
\alpha_{1}=0,3, \beta_{1}=0,25, \alpha_{2}=-0,12, \beta_{2}=0,05,
$$




$$
\alpha_{3}=0,55, \beta_{3}=0,3, \alpha_{4}=-0,45, \beta_{4}=0,07 \text {, }
$$

(b) Numbers of units:

$$
\begin{gathered}
\gamma_{1}=0,25, \theta_{1}=0,05, \gamma_{2}=-0,45, \theta_{2}=0,1, \\
\gamma_{3}=0,7, \theta_{3}=0,25, \gamma_{4}=0,3, \theta_{4}=0,03 .
\end{gathered}
$$

Without loss of generality, it is assumed that $p_{i}(0)=q_{i}(0)=1$ for each $i \in\{1,2, \ldots, 4\}$. Some realizations of prices and numbers of units proccesses are presented in Figure 1 and Figure 2.
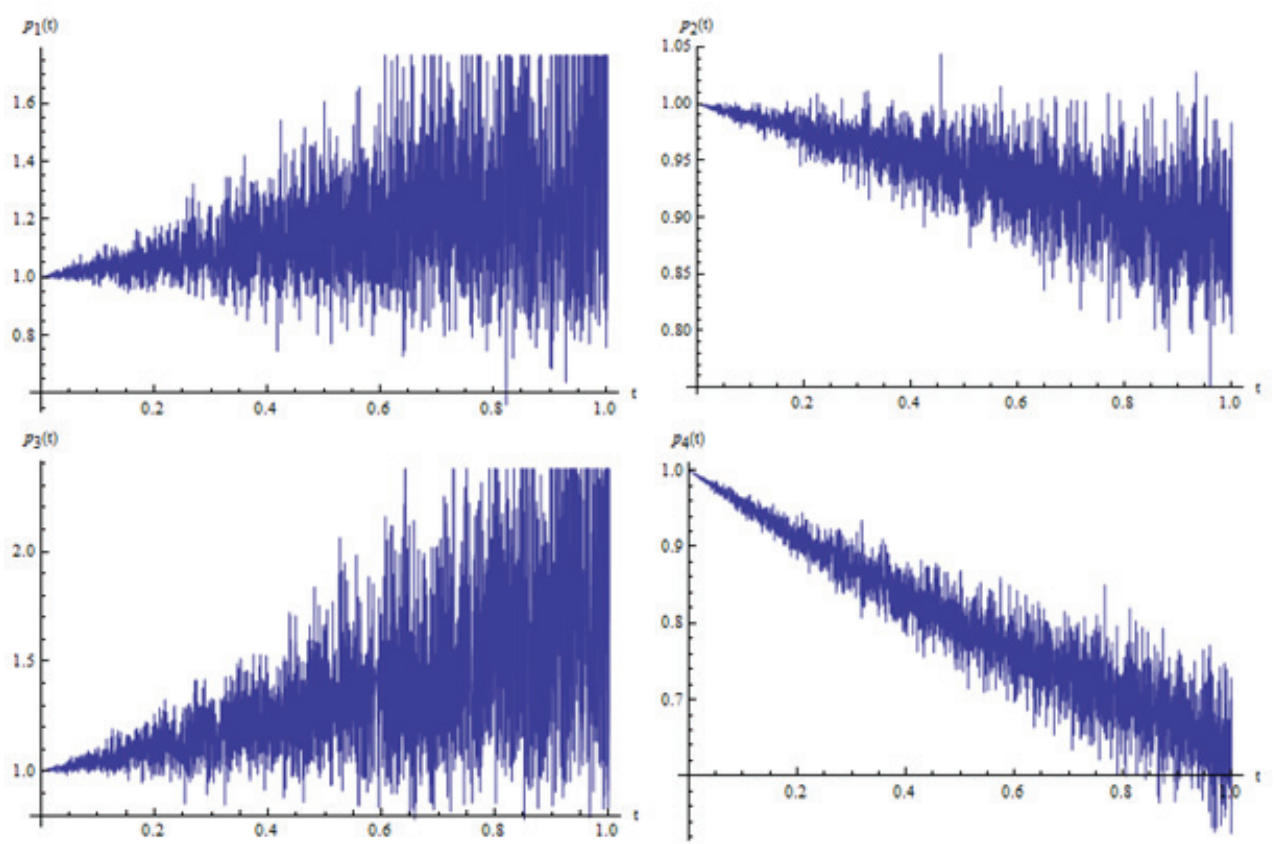

Figure 1. Some realizations of prices of units processes $p_{1}(t), p_{2}(t), p_{3}(t)$ and $p_{4}(t)$
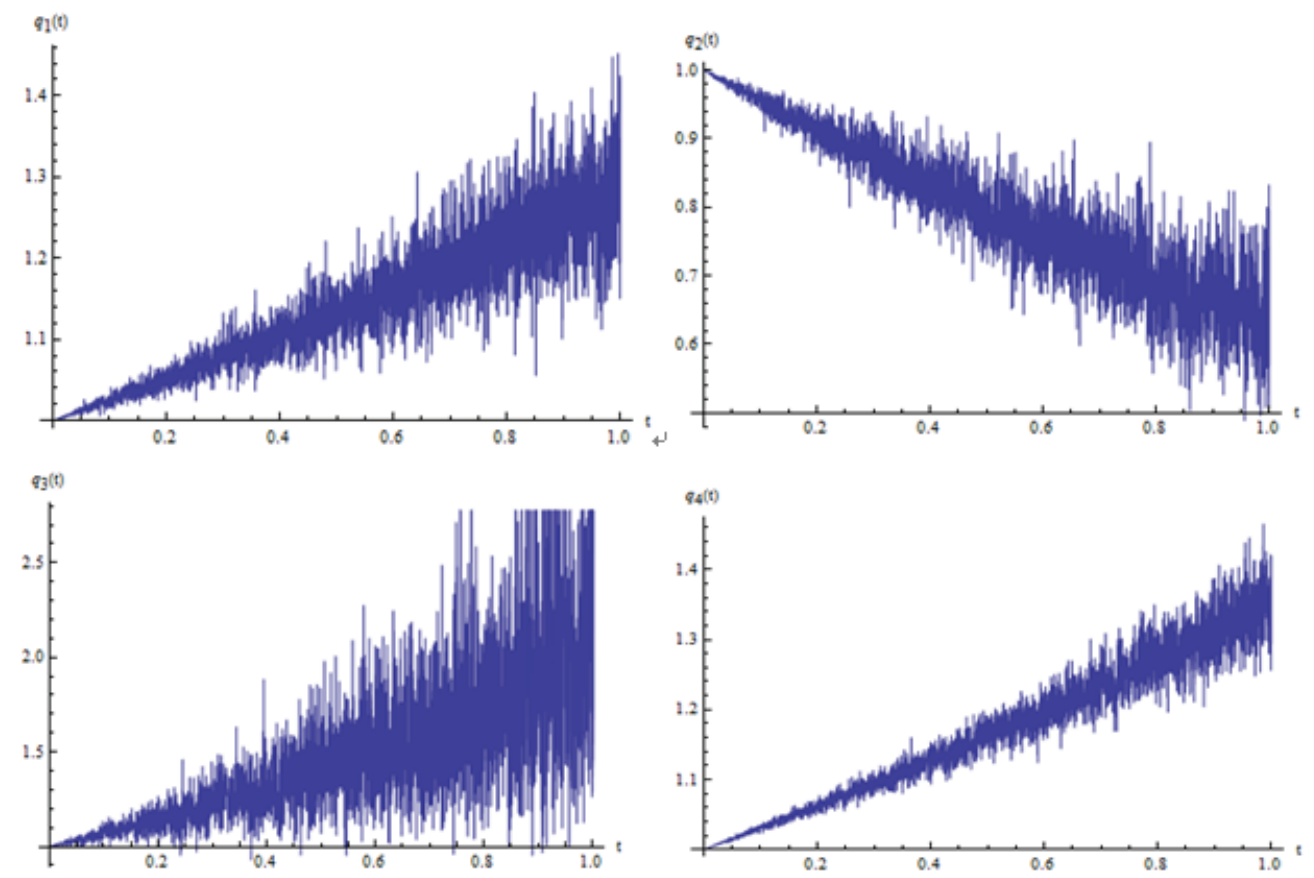

Figure 2. Some realizations of numbers of units processes $q_{1}(t), q_{2}(t), q_{3}(t)$ and $q_{4}(t)$ 
Some realization of the average return rate $R_{P}(0, t)$ for $t \in[0,1]$ is presented in Figure 3 . The generated values of index $R_{P}(0,1)$ for each of $i^{t h}$ realization of price and quantity processes $\left(R_{P i}(0,1): i=1,2, \ldots, 100\right)$ are presented in Figure 4.

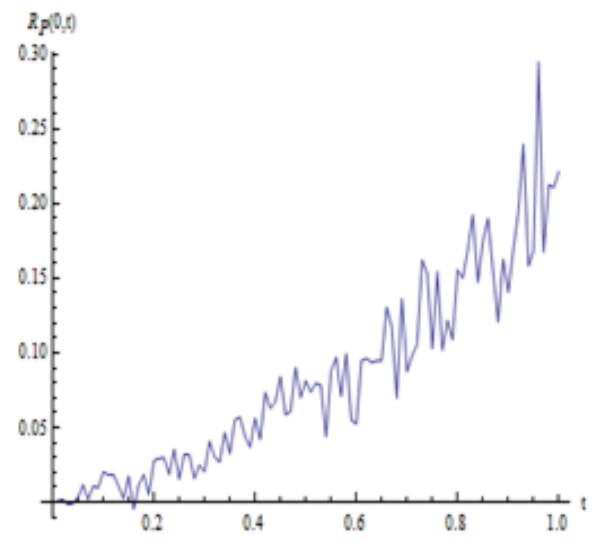

Figure 3. Realization of $R_{P}(0, t)$ process

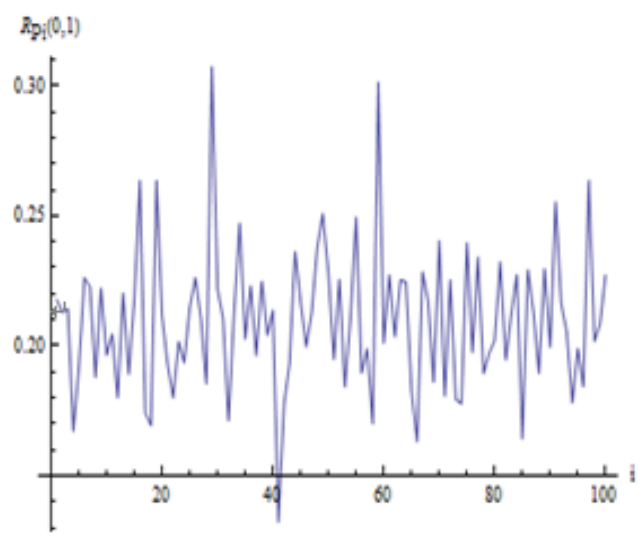

Figure 4. Generated values of index $R_{P}(0,1)$

The stochastic version of the average rate of return of funds $R_{P}(0,1)$ is then compared with average rates of return $\bar{r}_{G K}(0,1)$ and $\bar{r}_{B}(0,1)$ for which we divide the time interval $[0,1]$ into ten subintervals of the same length. It is found that, for $n=10000$ generated realizations of prices of units and numbers of units processes are presented in Table 1 (to read more about estimation of mean value and variance and the bias of this estimation see Żadło (2006), Małecka (2011) or Papież and Śmiech (2013).

Table 1. Basic parameters of average return rates

\begin{tabular}{lccc}
\hline Parameter & $R_{P}(0,1)$ & $\bar{r}_{B}(0,1)$ & $\bar{r}_{G K}(0,1)$ \\
\hline Mean & 0,233 & 0,432 & 0,479 \\
Standard deviation & 0,020 & 0,216 & 0,238 \\
Median & $\mathbf{0 , 2 3 2}$ & $\mathbf{0 , 2 4 1}$ & $\mathbf{0 , 2 7 3}$ \\
Median deviation & 0,014 & 0,141 & 0,130 \\
\hline
\end{tabular}

\section{Conclusions}

The form of the $R_{p}$ measure seems to be proper-in the deterministic case, where $\beta_{i}(t)=0$, it can be expressed by using some known chain indices (Divisia, Cobb-Douglas). The known $\bar{r}_{G K}$ and $\bar{r}_{B}$ measures have the same property in a discrete version. Moreover, the stochastic $R_{p}$ measure takes into account the volatility of unit prices and number of units $\left(\beta_{i}\right.$ and $\theta_{i}$ parameters). In the simulation study only $R_{P}(0,1)$ rate has small standard deviation and median deviation. The distribution of $R_{P}(0,1)$ is quasi-symmetric (mean and median are almost equal), no extreme realizations exist, while in the other two distributions of $\bar{r}_{B}(0,1)$ and $\bar{r}_{G K}(0,1)$ the mean is higher than the median and thus these distributions are skewed to the right. We conclude that some extreme realizations of price or (and) quantity processes lead to extreme values of the considered chain indices. Using medians, instead of means, for our comparison and thus ruling out these extreme realizations we obtain smaller differences between compared measures (for example: 0,232 in case of $R_{P}(0,1)$ and 0,241 in case of $\bar{r}_{B}(0,1)$ ).

Apart from measuring fund return rates, the proposed formula could be used to measure the mean efficiency of any class of investable assets, and in particular mutual funds. If the class is too broad to be completely enumerated, a representative sample might be chosen according to various criteria of representativeness discussed by Kruskal (1979) and Gamrot (2008).

\section{Acknowledgements}

The authors would like to thank the Editor and the reviewers for their helpful comments on an earlier version of the manuscript which have led to an improvement of this paper. 


\section{References}

Banarjee, K. S. (1979). A note on the Divisia indices. Statistische Hefte, 20, $172-175$. http://dx.doi.org/10.1007/BF02932776

Białek, J. (2005). Jak mierzyć rentowność grupy funduszy emerytalnych? Model stochastyczny. In: Modelowanie Preferencji a Ryzyko'05, Praca zbiorowa pod redakcją naukową Tadeusza Trzaskalika, Wydawnictwo Akademii Ekonomicznej w Katowicach, Katowice, 329-343.

Białek, J. (2008). New definition of the average rate of return of a group of pension funds. In Financial Markets: Principles of Modelling, Forecasting and Decision-Making, Łódź, 126-135.

Białek, J. (2009). The Proposition of Maesure of Pension Fund's Effectiveness. Acta Universitatis Lodziensis, Folia Oeconomica, 228, 331-339.

Białek, J. (2012). Zastosowanie statystycznych indeksów tańcuchowych do oceny przeciętnego zwrotu grupy OFE. In: Inwestycje finansowe i ubezpieczenia-tendencje światowe a polski rynek, Wrocław, 2012.

Gajek, L., \& Kałuszka, M. (2000). On the average return rate for a group of investment funds. Acta Universitas Lodziensis, Folia Oeconomica, 152, 161-171.

Gajek, L., \& Kałuszka, M. (2001). On some properties of the average rate of return-a discrete time stochastic model, Working paper.

Gajek, L., \& Kałuszka, M. (2002). On some properties of the average rate of return-a continuous time stochastic model, Working paper.

Gamrot, W. (2007). Mean Value Estimation Using Two-Phase Samples with Missing Data in Both Phases. Acta Appl. Math., 96, 215-220. http://dx.doi.org/ 10.1007/s10440-007-9110-5

Gamrot, W. (2008). Representative Sample Selection via Random Search with Application to Surveying Communication Lines. In P. Rehorova, K. Marsikova, \& Z. Hubinka (Eds.), Proceedings of 26th International Conference, Mathematical Methods in Economics 2008. Technical University of Liberec, Czech Republic, 125-131.

Hull, J. (2009). Options, Futures, and other Derivatives (7th ed.). New Jersey: Prentice Hall.

Hulten, C. R. (1973). Divisia Index Numbers. Econometrica, 41, 1017-1025.

Ito, K. (1951). On stochastic differential equations. Memoirs, American Mathematical Society, 4, 1-51.

Karatzas, I., \& Shreve, S. (1991). Brownian Motion and Stochastic Calculus (2nd ed.). Springer.

Koo, H. (1998). Consumption and portfolio selection with labor income: a continuous time approach. Mathematical Finance, 8, 49-65.

Kruskal, W., \& Mosteller, F. (1979). Representative Sampling III: the Statistical Literature. International Statistical Review, 47, 245-265.

Małecka, M. (2011). Prognozowanie zmienności indeksów giełdowych przy wykorzystaniu modelu klasy GARCH. Ekonomista, 6, 843-860.

Oksendal, B. K. (2002). Stochastic Differential Equations: An Introduction with Applications. Springer.

Papież, M., \& Śmiech, S. (2013). Causality in mean and variance within the international steam coal market. Energy Economics, 36, 594-604.

Polish Pension Reform Package. (1997). Office of Government Plenipotentiary for Social Security Reform.

Szymańska, A. (2013). The use of asymmetric loss function for estimating premium rates in motor insurance. In M. Papież \& S. Śmiech (Eds.), Proceedings of $7^{\text {th }}$ Professor Aleksander Zeliaś International Conference on Modelling and Forecasting of Socio-Economic Phenomena. Cracow University of Economics, Poland, 181-189.

Von der Lippe, P. (2007). Index Theory and Price Statistics. Frankfurt, Germany: Peter Lang.

Żąłło, T. (2006). On prediction of total value in incompletely specified domains. Australian \& New Zealand Journal of Statistics, 48, 269-283. http://dx.doi.org/ 10.1111/j.1467-842X.2006.00440.x 


\section{Appendix}

\section{Theorem}

$$
R_{A}\left(T_{1}, T_{2}\right)+1=\left(R_{P}\left(T_{1}, T_{2}\right)+1\right)\left(R_{Q}\left(T_{1}, T_{2}\right)+1\right)
$$

Proof. Let us signify the relative changes of assets, prices and numbers of units as follows

$$
\tilde{A}=R_{A}\left(T_{1}, T_{2}\right)+1, \quad \tilde{P}=R_{p}\left(T_{1}, T_{2}\right)+1, \quad \tilde{Q}=R_{Q}\left(T_{1}, T_{2}\right)+1,
$$

to prove that $\tilde{A}=\tilde{P} \tilde{Q}$.

Let us assume the following:

$$
\alpha_{i}(t)=\alpha_{i} p_{i}(t), \quad \beta_{i}(t)=\beta_{i} p_{i}(t), \quad \gamma_{i}(t)=\gamma_{i} q_{i}(t) \quad \text { and } \quad \theta_{i}(t)=\theta_{i} q_{i}(t) .
$$

Thus, from Equations (8) and (10), we get:

$$
\begin{aligned}
& d p_{i}(t)=\alpha_{i}(t) d t+\beta_{i}(t) d W_{i}(t), \\
& d q_{i}(t)=\gamma_{i}(t) d t+\theta_{i}(t) d W_{i}(t) .
\end{aligned}
$$

Firstly, from the Ito theorem (Ito, 1951) we have:

$$
d A(t)=d\left(\sum_{i=1}^{n} p_{i}(t) q_{i}(t)\right)=\sum_{i=1}^{n} d\left(p_{i}(t) q_{i}(t)\right)=\sum_{i=1}^{n} p_{i}(t) d q_{i}(t)+\sum_{i=1}^{n} q_{i}(t) d p_{i}(t)+\sum_{i=1}^{n} \beta_{i}(t) \theta_{i}(t) d t . \quad(A-5)
$$

From $(A-3),(A-4)$ and $(A-5)$ we obtain:

$$
\begin{aligned}
d A(t) & =\sum_{i=1}^{n} p_{i}(t)\left(\gamma_{i}(t) d t+\theta_{i}(t) d W_{i}(t)\right)+\sum_{i=1}^{n} q_{i}(t)\left(\alpha_{i}(t) d t+\beta_{i}(t) d W_{i}(t)\right)+\sum_{i=1}^{n} \beta_{i}(t) \theta_{i}(t) d t \\
& =\left(\sum_{i=1}^{n} p_{i}(t) \gamma_{i}(t)+\sum_{i=1}^{n} q_{i}(t) \alpha_{i}(t)+\sum_{i=1}^{n} \beta_{i}(t) \theta_{i}(t)\right) d t+\sum_{i=1}^{n}\left(p_{i}(t) \theta_{i}(t)+q_{i}(t) \beta_{i}(t) d W_{i}(t)\right. \\
& =\Psi(t) d t+\sum_{i=1}^{N} B_{i}(t) d W_{i}(t),
\end{aligned}
$$

where

$$
\Psi(t)=\sum_{i=1}^{N} p_{i}(t) \gamma_{i}(t)+\sum_{i=1}^{N} q_{i}(t) \alpha_{i}(t)+\sum_{i=1}^{N} \beta_{i}(t) \theta_{i}(t)
$$

and,

$$
B_{i}(t)=p_{i}(t) \theta_{i}(t)+q_{i}(t) \beta_{i}(t) .
$$

Using the Ito theorem for the function $f(t, x)=\ln x$ and formula $(A-6)$ we get

$$
d(\ln A(t))=\left(\frac{\Psi(t)}{A(t)}-\frac{\sum_{i=1}^{n} B_{i}^{2}(t)}{2 A^{2}(t)}\right) d t+\frac{\sum_{i=1}^{n} B_{i}(t) d W_{i}(t)}{A(t)} .
$$

Since (Note 4)

$$
\tilde{A}=\frac{A\left(T_{2}\right)}{A\left(T_{1}\right)}=\exp \left(\int_{T_{1}}^{T_{2}} d(\ln A(t))\right.
$$

from $(A-10)$ we get

$$
\tilde{A}=\exp \left(\int_{T_{1}}^{T_{2}}\left(\frac{\Psi(t)}{A(t)}-\frac{\sum_{i=1}^{n} B_{i}^{2}(t)}{2 A^{2}(t)}\right) d t+\sum_{i=1}^{n} \int_{T_{1}}^{T_{2}} \frac{B_{i}(t) d W_{i}(t)}{A(t)}\right) .
$$


From Equations $(A-7),(A-8)$ and $(A-11)$, we obtain

$$
\begin{aligned}
\tilde{A}= & \exp \left[\int _ { T _ { 1 } } ^ { T _ { 2 } } \left(\frac{\sum_{i=1}^{n} p_{i}(t) \gamma_{i}(t)+\sum_{i=1}^{n} q_{i}(t) \alpha_{i}(t)+\sum_{i=1}^{n} \beta_{i}(t) \theta_{i}(t)}{A(t)}-\right.\right. \\
& \left.\left.-\frac{\sum_{i=1}^{n}\left(p_{i}^{2}(t) \theta_{i}^{2}(t)+q_{i}^{2}(t) \beta_{i}^{2}(t)+2 A_{i}(t) \theta_{i}(t) \beta_{i}(t)\right.}{2 A^{2}(t)}\right) d t\right] \times \\
& \times \exp \left[\sum_{i=1}^{n} \int_{T_{1}}^{T_{2}} \frac{p_{i}(t) \theta_{i}(t)}{A(t)} d W_{i}(t)+\sum_{i=1}^{n} \int_{T_{1}}^{T_{2}} \frac{q_{i}(t) \beta_{i}(t)}{A(t)} d W_{i}(t)\right] \\
= & \exp \left(\int_{T_{1}}^{T_{2}}\left(\frac{\sum_{i=1}^{n} q_{i}(t) \alpha_{i}(t)}{A(t)}+\frac{\sum_{i=1}^{n} \beta_{i}(t) \theta_{i}(t)}{2 A(t)}-\frac{\sum_{i=1}^{n} q_{i}^{2}(t) \beta_{i}^{2}(t)}{2 A^{2}(t)}-\frac{\sum_{i=1}^{n} A_{i}(t) \beta_{i}(t) \theta_{i}(t)}{2 A^{2}(t)}\right) d t\right. \\
& \left.+\sum_{i=1}^{n} \int_{T_{1}}^{T_{2}} \frac{q_{i}(t) \beta_{i}(t)}{A(t)} d W_{i}(t)\right) \times \exp \left(\int _ { T _ { 1 } } ^ { T _ { 2 } } \left(\frac{\sum_{i=1}^{n} p_{i}(t) \gamma_{i}(t)}{A(t)}+\frac{\sum_{i=1}^{n} \beta_{i}(t) \theta_{i}(t)}{2 A(t)}-\frac{\sum_{i=1}^{n} p_{i}^{2}(t) \theta_{i}^{2}(t)}{2 A^{2}(t)}-\right.\right. \\
& \left.-\frac{\sum_{i=1}^{n} A_{i}(t) \beta_{i}(t) \theta_{i}(t)}{2 A^{2}(t)} d t+\sum_{i=1}^{n} \int_{T_{1}}^{T_{2}} \frac{p_{i}(t) \theta_{i}(t)}{A(t)} d W_{i}(t)\right) .
\end{aligned}
$$

From $(A-1)$ and $(A-12)$ we get

$$
\begin{aligned}
\tilde{A}= & \exp \left(\int_{T_{1}}^{T_{2}}\left(\frac{\sum_{i=1}^{n} A_{i}(t) \alpha_{i}}{A(t)}+\frac{\sum_{i=1}^{n} A_{i}(t) \beta_{i} \theta_{i}}{2 A(t)}-\frac{\sum_{i=1}^{n} A_{i}^{2}(t) \beta_{i}^{2}}{2 A^{2}(t)}-\frac{\sum_{i=1}^{n} A_{i}^{2}(t) \beta_{i} \theta_{i}}{2 A^{2}(t)}\right) d t+\sum_{i=1}^{n} \int_{T_{1}}^{T_{2}} \frac{A_{i}(t) \beta_{i}}{A(t)} d W_{i}(t)\right) \times \\
& \times \exp \left(\int_{T_{1}}^{T_{2}}\left(\frac{\sum_{i=1}^{n} A_{i}(t) \gamma_{i}}{A(t)}+\frac{\sum_{i=1}^{n} A_{i}(t) \beta_{i} \theta_{i}}{2 A(t)}-\frac{\sum_{i=1}^{n} A_{i}^{2}(t) \theta_{i}^{2}}{2 A^{2}(t)}-\frac{\sum_{i=1}^{n} A_{i}^{2}(t) \beta_{i} \theta_{i}}{2 A^{2}(t)}\right) d t+\sum_{i=1}^{n} \int_{T_{1}}^{T_{2}} \frac{A_{i}(t) \theta_{i}}{A(t)} d W_{i}(t)\right) \\
= & \tilde{P} \cdot \tilde{Q} .
\end{aligned}
$$

\section{Notes}

Note 1. In Poland, in 2001 and 2002 Bankowy Fund did not reach the minimal rate of return.

Note 2. Geometric Brownian Motion is used to model stock prices in the BlackCScholes model and is the most widely used model of stock price behavior (Hull, 2009).

Note 3. The chosen parameters of prices of units and numbers of units describe many of funds condition variants: increasing or decreasing prices of units and number of units with small or high volatility. Nevertheless, the simulation study plays a role of some illustration of the presented measures and all conclusions from that study can not be general.

Note 4. In (27) we use Ito integral.

\section{Copyrights}

Copyright for this article is retained by the author(s), with first publication rights granted to the journal.

This is an open-access article distributed under the terms and conditions of the Creative Commons Attribution license (http://creativecommons.org/licenses/by/3.0/). 